\title{
Rab coupling protein (RCP): a novel target of progesterone action in primate endometrium
}

\author{
V S Patil, G Sachdeva, D N Modi, R R Katkam, D D Manjramkar, I Hinduja ${ }^{1}$ and C P Puri
}

Primate Biology Department, National Institute for Research in Reproductive Health, Indian Council of Medical Research, Parel, Mumbai 400012 , India

${ }^{1}$ INKUS IVF Centre, Charni Road, Mumbai, India

(Requests for offprints should be addressed to G Sachdeva; Email: ritugeet@ vsnl.net)

\begin{abstract}
Acquisition of functional receptivity by the endometrium is assumed to be effected by progesterone-dependent expression and repression of several genes during the implantation window in a menstrual cycle. In the present study, we employed differential display (DD) reverse transcription-polymerase chain reaction (RT-PCR) to identify progesterone-dependent gene/gene fragments that are differentially expressed during the peri-implantation phase in receptive and nonreceptive endometria, obtained from fertile and infertile bonnet monkeys respectively. Receptive endometria were obtained from regularly cycling $(n=5)$ fertile female bonnet monkeys. Endometrial nonreceptivity was induced by treating bonnet monkeys with either $2.5 \mathrm{mg}(n=5)$ or $5.0 \mathrm{mg}(n=5)$ onapristone (ZK 98.299), an antiprogestin, on every third day for one cycle. Ovulation, levels of circulatory hormones (estradiol and progesterone) and menstrual cycle length did not change in treated animals; however, endometrial growth was retarded. DD2, one of the differentially expressed cDNA fragments, showed higher representation in nonreceptive endometria than in receptive endometria. The DD2 sequence was found to be homologous to the sequence of the carboxyl terminal region of Rab coupling protein (RCP), a recently discovered protein involved in intracellular vesicular trafficking. To confirm the identity of DD2 as RCP, RT-PCR studies were carried out with a forward primer deduced from the RCP sequence and a reverse primer from the DD2 sequence. The product (DDRCP) obtained, when sequenced, revealed 95\% homology with the nucleotide number 1196-1757 of human RCP cDNA. Furthermore, the pattern of DDRCP expression at transcript level was found to be similar to that shown by DD2; that is, it was higher in nonreceptive endometrium. Northern analysis using labeled DD2 or DDRCP cDNA fragments identified two transcripts of 6.0 and $4.0 \mathrm{~kb}$ in human endometrium. In situ hybridization studies using digoxigenin-labeled DD2 revealed significantly higher $(P<0.05)$ localization of endometrial RCP transcripts in the proliferative phase than in the peri-implantation phase in control animals. The localization was also significantly $(P<0.01)$ higher in peri-implantation-phase endometria from antiprogestin-treated animals than in control animals. These antiprogestin-treated animals, however, did not demonstrate any concomitant increase in the levels of immunoreactive endometrial Rab4 and Rab11 during the peri-implantation phase. A similar pattern of cycle-dependent RCP expression was observed in human endometrial biopsies. Furthermore, significantly higher $(P<0.05)$ levels of RCP transcripts were detected during the periimplantation phase in women with unexplained infertility $(n=3)$ than in fertile women $(n=3)$. This is the first report indicating the endometrial expression of RCP and its hormonal regulation.
\end{abstract}

Journal of Molecular Endocrinology (2005) 35, 357-372

\section{Introduction}

The endometrium is a highly dynamic tissue with a remarkable ability to change its form and function in response to various stimuli such as hormones, an implanting conceptus, contraceptives, receptor modulators, neoplastic and metaplastic agents, and infections (Giudice 2003). Among these, ovarian hormones, that is, estradiol and progesterone, because of their physiologic relevance, have been studied extensively for their role in endometrial growth, differentiation and other specialized functions such as implantation and maintenance of pregnancy (Fazleabas et al. 1999, Spencer \& Brazer 2002, Albrecht et al. 2003, Albrecht \& Pepe 2003).
It has been unequivocally established that progesterone is indispensable for endometrial maturation in primates (Rosario et al. 2003). Our previous studies have demonstrated that the endometrium is more sensitive than the pituitary-hypothalamo-ovarian axis to any event that blocks either progesterone availability or action (Ishwad et al. 1993, Katkam et al. 1995). Furthermore, sufficient data exist to suggest that the progesterone-mediated endometrial maturation is an outcome of the interplay between various genes or gene products (Ace \& Okulicz 1995, 1999, 2004, Horcajadas et al. 2004). When deprived of optimal progesterone action, the endometrium displays derangements in the expression of a number of molecules such as cell 
adhesion molecules (integrins), cytokines (leukemia inhibitory factor), growth factors (transforming growth factor beta) and several secretory proteins (Sachdeva et al. 2001, Lessey 2002, Catalano et al. 2003).

From the large body of available data, it is apparent that several efforts have been made to understand the functions of single molecules and pathways in endometrium exposed to progesterone (Wang et al. 2003, Haendler et al. 2004, Kitaya et al. 2004). However, the approach of scanning the endometrial transcriptomes during the peri-implantation phase, in the presence and absence of progesterone action, promises to offer not only a holistic view of the role of progesterone in endometrial receptivity, but also the identification of novel molecules that have never been investigated for their role in endometrial receptivity.

We employed differential display (DD) reverse transcription-polymerase chain reaction (RT-PCR) to scan the global changes in the endometrial transcriptome after the neutralization of progesterone action, using an antiprogestin (ZK98.299) in bonnet monkeys. Our previous studies have demonstrated the ability of antiprogestins to impair endometrial function and induce infertility without disrupting the pituitaryhypothalamo-ovarian axis in bonnet monkeys (Katkam et al. 1995). Antiprogestins at selected dosages did not alter the circulatory levels of progesterone and estradiol and the length of menstrual cycle in these animals but rendered them infertile by retarding endometrial growth. We compared the endometrial RNA profile of these animals during the peri-implantation phase with that of fertile untreated animals. In this study, we present the data on one of the differentially expressed cDNA fragments that showed overrepresentation in nonreceptive endometria from antiprogestin-treated animals. The role of this differentially expressed fragment in endometrial receptivity and its hormonal regulation was hitherto unknown in primates. Ours is the first report to demonstrate the expression of this gene in primate endometrium. The present study also hints at the regulatory role of progesterone in the expression of this gene.

\section{Materials and methods}

The use of animal and human samples for the present study was approved by the respective ethics committees of the institute.

\section{Animals}

Twenty female bonnet monkeys, each weighing $3 \cdot 5-4.5 \mathrm{~kg}$ and showing at least two consecutive ovulatory menstrual cycles of 28-30 days, were admitted to the study. Levels of circulating estradiol and progesterone in these animals were determined by specific radioimmunoassays as described previously (Katkam et al. 1995). The inter- and intra-assay coefficients of variation were $9 \cdot 2$ and $6.8 \%$ respectively for estradiol and 11.1 and $6.7 \%$ respectively for progesterone. Onapristone-ZK 98.299 (a kind gift from Dr Walter Elger, Schering, Germany), an antiprogestin, at doses of $2.5 \mathrm{mg}(n=5)$ and $5.0 \mathrm{mg}(n=5)$ dissolved in vehicle (benzyl benzoate: castor oil, 9:1), was injected subcutaneously into the animals on day 1 of their menstrual cycle and continued every third day for one cycle until the day of biopsy. We have previously reported $100 \%$ efficacy of this treatment regimen in inhibiting implantation in bonnet monkeys (Katkam et al. 1995). In control animals $(n=5)$, which were treated with the vehicle alone, basal and peak levels of estradiol were $50-75 \mathrm{pg} / \mathrm{ml}$ and $300-600 \mathrm{pg} / \mathrm{ml}$ respectively. Treatment with onapristone did not alter the circulating hormonal profile. Peri-implantation-phase or secretoryphase endometrial biopsies were collected on day 8 after the midcycle estradiol peak (that is, day 20 of the cycle) from control and treated animals and also from two progesterone-insufficient animals (midcycle circulating progesterone levels under $2 \mathrm{ng} / \mathrm{ml}$ ). Proliferative phase biopsies were obtained on day 8 of the menstrual cycle (estradiol levels over $200 \mathrm{pg} / \mathrm{ml}$ ) from three control animals. A part of the endometrial tissue was fixed immediately in 10\% neutral buffered formalin and embedded in paraffin for in situ hybridization analysis and immunohistochemical analysis, while the remaining tissue was frozen at $-70{ }^{\circ} \mathrm{C}$ until use.

\section{Humans}

Women attending the infertility clinics at the institute and INKUS IVF centre were admitted to the study after obtaining their informed, written consent. The control group included healthy, regularly cycling female partners $(n=10)$ of the infertile couples. Routine semenology tests by the andrologist had revealed abnormal semen profiles in their male partners. They either had low sperm count $(<20 \mathrm{million} / \mathrm{ml})$ or very low sperm motility $(<50 \%$ sperm with forward motility) or abnormal sperm morphology $(<30 \%$ with normal forms). The test group included regularly cycling women with unexplained or secondary infertility. Male partners of these women did not show any abnormality in sperm count, motility or morphology.

Endometrial aspirates were collected from the control group during either proliferative, midluteal or late luteal phases of the cycles and from the infertile group during the midluteal phase. Estradiol and progesterone levels on the day of biopsy in fertile and infertile women did not show any significant deviation from the expected levels. Estradiol levels during the proliferative phase were $180 \pm 60 \mathrm{pg} / \mathrm{ml}$; during the midluteal phase, 
Table 1 Sequence of oligonucleotide/primers/probes used for DD-RT-PCR, RT-PCR and in situ hybridization studies

Name of oligo/primer/probe
V1
V2
V3
V16
V12
V10
GR1
DD2.1
DD2.2
RCP1
RCP2
ACTIN1
ACTIN2
ER ANTISENSE

PR ANTISENSE

$18 \mathrm{~S} 1$

$18 \mathrm{~S} 2$
Sequence $\left(5^{\prime}-3^{\prime}\right)$

CCTCCTGCGAAGCTTTTTTTTTTTTTTG
CCTCCTGCGAAGCTTTTTTTTTTTTC
CCTCCTGCGAAGCTTTTTTTTTTTTA
TGCGAAGCTTTTTTTTTTTTGT
GACCTCTAGATGCTGTTGCC
GACCTCTAGATGCTGTTGTC
TACAACGAGC
ACAACGAGGCCATGATGAA
CAACCTGAGTCGGGATGC
GAAAATTGGAGGTCTCGGTTCA
GCTTCCACCAAGGACTCCTTGA
GTTGCTATCCAGGCTGTGCT
GGCCATCTCTCTTGCTCGAAGT
GTTCAGGGGCTCCAGCTCGTTCCCTTGGATC
TGATGCAGTAGGGC
TAAGGCGTGATTGAGAGGCAGGATATAGGCACG
TGGATGAAATCCATCACGGTGGT
CGATGCTCTTAGCTGAGTGT
GGAACTACGACGGTATCTGA

$200 \pm 30 \mathrm{pg} / \mathrm{ml}$; and during the late luteal phase, $120 \pm 40 \mathrm{pg} / \mathrm{ml}$. Progesterone levels during the proliferative phase were $0.8 \pm 0.13 \mathrm{ng} / \mathrm{ml}$; during the midluteal phase, $11.5 \pm 1 \cdot 0 \mathrm{ng} / \mathrm{ml}$; and during the late luteal phase, $5 \cdot 8 \pm 1 \cdot 0 \mathrm{ng} / \mathrm{ml}$.

\section{RNA extraction}

Total RNA samples were extracted from endometrial biopsies/aspirates with the RNeasy Minikit (Qiagen) as suggested by the manufacturer. RNA samples were incubated with RNase free DNase I (Roche) at $37^{\circ} \mathrm{C}$ for $30 \mathrm{~min}$ and repurified through RNeasy Minikit columns. All RNA samples were first normalized for $\beta$ actin according to the protocol detailed previously (Sachdeva et al. 2001). Wherever required, samples were also normalized for $18 \mathrm{~S}$ rRNA transcript levels.

\section{Differential display RT-PCR (DD-RT-PCR)}

DD-RT-PGR was carried out by the protocol described by Liang and Pardee (1992) with some modifications. All primers were custom synthesized by Gibco BRL, (Life Technologies, Gaithersburg, MD, USA). All reactions were carried out thrice for all samples. Briefly, $1 \mu \mathrm{g}$ RNA sample was reverse-transcribed with $50 \mathrm{U}$ of AMV reverse transcriptase (Roche) in the presence of $50 \mathrm{ng}$ $\mathrm{V} 1, \mathrm{~V} 2$ or V3 anchored primers (Table 1) and $0 \cdot 2 \mu \mathrm{M}$ dNTPs (Roche) at $37^{\circ} \mathrm{C}$ for $1 \mathrm{~h}$. One-tenth of this reaction was then amplified in a PCR containing $50 \mu \mathrm{M}$


$3000 \mathrm{Ci} / \mathrm{mM}$; BRIT, Hyderabad, India), 0.2 $\mu \mathrm{M}$ each of the two primers - a modified anchored $\mathrm{T}$ oligo- nucleotide primer and one of the arbitrary primers (Table 1) - and $1 \mathrm{U}$ of Taq polymerase. The cycling parameters for PCR were as follows: an initial denaturation of $94^{\circ} \mathrm{C}$ for $2 \mathrm{~min}$ followed by 30 cycles of $94{ }^{\circ} \mathrm{C}$ for $30 \mathrm{~s}, 42{ }^{\circ} \mathrm{C}$ for $2 \mathrm{~min}$, and $72{ }^{\circ} \mathrm{C}$ for $30 \mathrm{~s}$ followed by a final extension of $72{ }^{\circ} \mathrm{C}$ for $7 \mathrm{~min}$. After PCR amplification in a MJ Research (Ramsey, Minnesota, USA) thermal cycler, the samples were analyzed on a $6 \%$ nondenaturing polyacrylamide sequencing gel, dried without fixation, and exposed on radiographic film (Amersham) for $72 \mathrm{~h}$. After analysis of the autoradiogram, Whatman pieces with the bands exhibiting differential expression were excised from the gel. DNA was eluted by boiling the dried Whatman pieces in $100 \mu \mathrm{l}$ water for $10 \mathrm{~min}$. DNA was ethanol precipitated, dried and resuspended in $10 \mu \mathrm{l}$ sterile water. The excised fragment was then reamplified by PCR using the corresponding pair of primers under the same conditions as described above, except that the radioisotope was not used. The PCR products were eluted from $2 \cdot 5 \%$ low-melt agarose gels. These products were subcloned into pGEMT vectors (Promega). The positive clones were subjected to nucleotide sequence analysis commercially.

\section{In silico analysis}

All cDNA homology searches were carried out with BLAST software at the NCBI database (www.ncbi.nih. gov/BLAST/). Nucleotide sequences were conceptually translated into amino-acid sequences with the translation tool at www.expasy.org/tools/dna.html. Candidate progesterone-responsive element (PRE) and 
estrogen-responsive element (ERE) sites were searched with the Transcription Element Search System (TESS) tool at www.cbil.upenn.edu/tess.

\section{Primer design}

Sequences of the DD2-specific primers (DD2.1 and DD2-2) and RCP-specific primers (RCP 1 and RCP 2) were deduced from the sequences of $\mathrm{DD} 2 \mathrm{cDNA}$ fragment and RCP respectively, using the Primer 3 tool (http://frodo.wi.mit.edu/cgi-bin/primer3/primer3 www.cgi). Human RCP sequence was available in the gene bank (Accession no. AF368294).

\section{Digoxigenin labeling of cDNA fragment}

An amount of $100 \mathrm{ng}$ gel-eluted DD2 cDNA fragment was labeled in a total volume of $20 \mu \mathrm{l}$ containing $2 \mu \mathrm{l}$ random hexamers, $2 \mu \mathrm{l}$ labeling mix and $1 \mu \mathrm{l}$ Klenow enzyme (digoxigenin DNA labeling kit; Roche) at $37^{\circ} \mathrm{C}$ overnight. Concentration of the labeled DNA and the labeling efficiency was checked as instructed by the manufacturer (Roche).

\section{Reverse transcription-polymerase chain reaction (RT-PCR)}

The relative levels of DD2, RCP or $\beta$ actin transcripts in human or monkey endometrial samples were measured by RT-PCR with gene specific primers. An amount of $200 \mathrm{ng}$ DNA-free RNA was reverse transcribed and amplified with the Titan single-step RT-PCR kit according to the manufacturer's instructions (Roche). Briefly, the reaction mixture of $25 \mu \mathrm{l}$ contained $0 \cdot 4 \mu \mathrm{M}$ each of forward and reverse primers, $200 \mu \mathrm{M}$ dNTP mix and $1 \mathrm{U}$ enzyme mix. The reverse transcription was carried out at $50{ }^{\circ} \mathrm{C}$ for $45 \mathrm{~min}$. This was followed by 35 cycles of amplification, each cycle comprising denaturation at $94{ }^{\circ} \mathrm{C}$ for $30 \mathrm{~s}$, annealing at $58{ }^{\circ} \mathrm{C}$ for $1 \mathrm{~min}$ and extension at $72{ }^{\circ} \mathrm{C}$ for $2 \mathrm{~min}$. The PCR product was run on $1-2 \%$ agarose gel, stained in ethidium bromide, visualized under a UV transilluminator and quantitated by the GelPro analyzer 3.1.00 (Media Cybernetics, Silver Spring, MD, USA). An aliquot of RT-PGR product obtained with RCP1 as the forward primer and DD2.2 as the reverse primer was used for hemi-nested PCR reactions. A volume of $1 \mu \mathrm{LT}-\mathrm{PCR}$ product was amplified for 35 cycles, using either DD2.1/DD2.2 or $\mathrm{RCP1/RCP2}$ as forward/reverse primers. For validation, DD2 and RCP products were run on $1 \%$ agarose gel, denatured, neutralized and Southern blotted onto nylon membrane (Roche). Southern hybridization with digoxigenin-labeled DD2 fragment, post-hybridization washings and detection were carried out by the protocol described elsewhere (Sachdeva et al. 2000).

\section{Northern hybridization}

The size of the transcript encoding DD2/RCP was determined by hybridizing the RNA blot with digoxigenin-labeled DD2 cDNA at a concentration of $25 \mathrm{ng} / \mathrm{ml}$ in ExpressHyb (Clontech) solution for $1 \mathrm{~h}$ at $68{ }^{\circ} \mathrm{C}$. The blot was washed sequentially, first in $2 \times \mathrm{SSC}, 0 \cdot 1 \% \mathrm{SDS}$ at room temperature three times for $10 \mathrm{~min}$ each, and then in $0 \cdot 1 \times \mathrm{SSC}, 0 \cdot 1 \% \mathrm{SDS}$ at $58{ }^{\circ} \mathrm{C}$ thrice for $10 \mathrm{~min}$ each. To detect the hybrids, the blot was incubated in antidigoxigenin antibody conjugated to alkaline phosphatase (diluted 1:5000 in blocking solution) for $2 \mathrm{~h}$. After extensive rinsing in $0 \cdot 1 \mathrm{M}$ maleic acid buffer $(\mathrm{pH} 7 \cdot 5)$, the detection was carried out according to the manufacturer's instructions (Roche).

\section{Nonradioactive in situ hybridization}

In situ hybridization to detect $D D 2$ transcripts by $c D N A$ probes

Sections of 5 - $\mu$ m-thick paraffin were dewaxed and hydrated through grades of alcohol. Prehybridization was carried out at $37^{\circ} \mathrm{C}$ for $30 \mathrm{~min}$ with $50 \mu \mathrm{l}$ prehybridization buffer containing $1 \times$ Denhardt's solution (Sigma), 50\% formamide (Gibco BRL), $500 \mu \mathrm{g} / \mathrm{ml}$ salmon sperm DNA (Roche) and $250 \mu \mathrm{g} / \mathrm{ml}$ yeast tRNA (Roche). The sections were hybridized at $42{ }^{\circ} \mathrm{C}$ overnight in $50 \mu \mathrm{l}$ prehybridization buffer with the addition of heat-denatured digoxigenin-labeled cDNA probe at a concentration of $25 \mathrm{ng} / \mu \mathrm{l}$. RNase-treated sections or those incubated without antibodies were used as negative controls. After overnight hybridization, the sections were stringently washed in $1 \times \mathrm{SSC}$ at $65^{\circ} \mathrm{C}$ for $3 \mathrm{~min}$ and in $2 \times \mathrm{SSC}$ at room temperature for $5 \mathrm{~min}$. After blocking in 2\% normal sheep serum, the sections were incubated in 1:500 diluted alkaline phosphataseconjugated antidigoxigenin antibody (Roche) at $4{ }^{\circ} \mathrm{C}$ overnight. Next day, the sections were washed briefly in $0 \cdot 1 \mathrm{M}$ Tris-NaCl buffer, $\mathrm{pH} 7 \cdot 5$, and equilibrated in $0 \cdot 1 \mathrm{M}$ Tris HCl buffer, $\mathrm{pH} 9 \cdot 5$, for $5 \mathrm{~min}$. The color reaction was carried out for $20 \mathrm{~min}$ in the dark, using 5-bromo-4-chloro-3-indol-phosphate (BCIP) as the substrate and nitro blue tetrazolium chloride (NBT) as a chromogen, according to the manufacturer's instructions (Roche). The color reaction was stopped, and the sections were mounted in aquamount.

In situ hybridization to detect estrogen receptor (ER) and progesterone receptor $(P R)$ transcripts using oligo probes

Antisense oligo probes for ER and PR were kindly donated by Karl Roth GmbH (Germany). The sequences of these probes are given in Table 1. Oligo probes were tail labeled with digoxigenin with the tail labeling kit (Roche) according to the manufacturer's instructions. The sections were hybridized with 
digoxigenin-labeled oligos at a concentration of $1 \mathrm{pg} / \mu \mathrm{l}$ without any denaturation. To confirm the specificity of mRNA signals, various control experiments were conducted where sense probes were used as negative controls. Sections were sequentially washed in $4 \times \mathrm{SSC}$, $2 \times \mathrm{SSC}$ and $1 \times \mathrm{SSG}$ for $10 \mathrm{~min}$ twice. Detection of the hybrids was carried out as described above. Hybridization experiments were performed thrice for each sample. All sections were viewed under brightfield with an Olympus B 60 microscope. The intensity of colored precipitates for all slides was evaluated by image analysis software (BioVis 1.42). Four areas from each section were randomly selected for each animal in all groups. The integrated optical density (IOD) in each area was calculated with the software. The IOD of the negative control was subtracted from the IOD of each experimental section for each animal in all groups. The mean, S.D. and S.E.M. were calculated for each group. Statistical analysis for the comparison between two groups was carried out with Student's $t$-test.

\section{Immunohistochemical analysis}

Endometrial sections were immunostained with specific polyclonal antibodies against Rab4 and Rab11 (Santa Cruz Biotechnology, Santa Cruz, CA, USA). The protocol used for immunostaining was similar to that described previously (Sachdeva et al. 2001). In brief, the sections were incubated in specific rabbit antibodies against Rab4 or Rab11 (diluted 1:10 in PBS) at $4{ }^{\circ} \mathrm{C}$ for overnight. In control sections, antibodies were omitted, and only PBS was added. This was followed by treatment with antirabbit biotinylated secondary antibodies (diluted 1:200 in 1.5\% normal rabbit serum in PBS) for $2 \mathrm{~h}$ at room temperature. Detection of the immunoprecipitates was done with avidin-biotin complex (ABC) prepared in PBS as recommended by the manufacturer (Santa Cruz Biotechnology). Sections were then treated with the chromogen diaminobenzidine (DAB) for 10$15 \mathrm{~min}$. The reactions were stopped in water, dehydrated and mounted in DPX medium. The intensities of colored immunolocalized products were evaluated by image analysis software (BioVis 1.42). Five areas from each section were scanned using frames spanning either glands or stroma, and the integrated optical density (IOD) in each area was calculated with the software. The IOD of the negative control was subtracted from the IOD of each experimental section for each animal in all groups. The mean, S.D. and S.E.M. were calculated for each group. Statistical analysis of the comparison between two groups for both antigens was carried out with Student's $t$-test.

\section{Endometrial explant cultures}

Endometrial aspirates obtained from fertile women were washed with DMEM (Dulbecco's Modified Eagle's
Medium). Pieces of endometrium of $2 \times 2 \mathrm{~mm}$ were incubated in DMEM at $37^{\circ} \mathrm{C}$ with $5 \% \mathrm{CO}_{2}$ under aseptic conditions. After $1 \mathrm{~h}$, the medium was replaced with fresh DMEM containing 10\% charcoal-stripped fetal calf serum and antibiotics. These cultures were supplemented with either estradiol $\left(10^{-8} \mathrm{M}\right)$ or progesterone $\left(10^{-7} \mathrm{M}\right)$ and grown for $14 \mathrm{~h}$. Control cultures were incubated for the same period without hormone supplementation. After incubation, total RNA was extracted from all cultures.

\section{Real-time PCR}

Real-time PCR analysis was carried out to quantitate the levels of DD2 and 18S rRNA transcripts in endometrial explants incubated in the presence and absence of steroids. Total RNA was extracted from these endometrial explants, and cDNAs were prepared by a first-strand cDNA synthesis kit (Invitrogen). Realtime PCRs were set up according to the iCycler manual (BioRad). A master mix of the following reaction components was prepared as follows (final concentration): $9.5 \mu \mathrm{l}$ water, forward primer $(0.4 \mu \mathrm{M})$, reverse primer $(0 \cdot 4 \mu \mathrm{M})$, and 1 SYBR Green I (BioRad). A volume of $2 \mu \mathrm{l}$ cDNA was added as the PCR template. The following iGycler run protocol was used: denaturation program $\left(95^{\circ} \mathrm{C}\right.$ for $\left.2 \mathrm{~min}\right)$, amplification and quantification program repeated 40 times $\left(95^{\circ} \mathrm{C}\right.$ for $30 \mathrm{~s}$, annealing temp for $30 \mathrm{~s}, 72{ }^{\circ} \mathrm{C}$ for $\left.30 \mathrm{~s}\right)$. The melting curve program $\left(50-95^{\circ} \mathrm{C}\right)$ was run with a heating rate of $1^{\circ} \mathrm{C}$ per second, continuous fluorescence measurement and a cooling step to $4{ }^{\circ} \mathrm{C}$. Analysis of melting curves allowed optimization of annealing temperatures for each amplification product. For each reaction, the crossing point $(\mathrm{Ct})$ (defined as the cycle number at which noise band intersects the fluorescent curves) was determined with the iCycler software (BioRad). PCRs were all set in triplicate, and the mean value of the three $\mathrm{Cts}$ was calculated. A no-template control $\left(\mathrm{H}_{2} \mathrm{O}\right.$ control) was analyzed for each master mix. Each assay was repeated thrice. In order to calculate amplification efficiencies (E) of each target cDNA, relative standard curves were generated with serial dilutions $(1: 10,1: 100,1: 1000$ and $1: 10000)$ of a linearized pGEMT plasmid containing the insert (18S rRNA or DD2 fragment). Standard curves were generated by the iCycler software. They were based on the $\mathrm{Ct}$ and the log value of the standard cDNA dilution. For each sample, the level of expression of the DD2 (target) was compared with the expression of $18 \mathrm{~S}$ rRNA (reference) gene. PCR efficiencies (E) were calculated for the standard curves for both target and reference. Expression ratios to compare the amplification of DD2 in control and treated conditions were calculated as $\mathrm{R}=\mathrm{E}$ target $\Delta \mathrm{Ct}$ target (control - treated) $/ \mathrm{E}$ reference $\triangle \mathrm{Ct}$ reference (control - treated).

Journal of Molecular Endocrinology (2005) 35, 357-372 


\section{Results}

Treatment with the antiprogestin, onapristone, $2 \cdot 5$ or $5.0 \mathrm{mg}$ on every third day for one cycle, did not alter the levels of estradiol and progesterone. These parameters were similar to those observed in the control group, thereby indicating no disruption in ovarian function after antiprogestin treatment. These results were consistent with our previous findings (Sachdeva et al. 2001).

\section{Differential display (DD) RT-PCR to identify differentially expressed transcripts in receptive and nonreceptive endometria}

Comparison of the peri-implantation-phase endometrial cDNA profiles of control and treated animals by DD-RT-PCR analysis, using different sets of arbitrary primer (as a forward primer) and anchored oligo dT primer (as a reverse primer), revealed the following three expression patterns:

1. equivalent representation in receptive and nonreceptive endometria

2. higher representation of certain cDNA fragments, that is, DDl in receptive endometria from control animals

3. higher representation in nonreceptive endometria from treated animals, that is, DD2A and DD2B (Fig 1A).

Higher expression of DD2B in the peri-implantationphase endometria from antiprogestin-treated animals than in control animals was also shown (Fig. 1B). A RT-PCR product of $219 \mathrm{bp}$ was detected with DD2B specific primers. Densitometric analysis of DD2 and actin RT-PCR products by image-analysis software and estimation of the ratios between DD2 and actin in each sample showed higher representation of DD2 transcripts in endometrial RNA samples from treated animals than from control animals.

\section{Sequence analysis of DD1, DD2A and DD2B}

The sequence of DD1 cDNA fragment (88 bp) showed partial homology with a region in the major histocompatibility complex (MHC) BAC clone from rhesus monkey (Macaca mulatta) (Accession no. AC148712).

DD2B (245 bp) was homologous to DD2A (124 bp) except for the presence of 121 additional bases at the $3^{\prime}$ end (Fig. 2). The sequence of DD2B showed 93\% homology with RCP mRNA (Accession no. AF 368294) at cDNA level. The 71-amino-acid open reading frame of the DD2B cDNA sequence shared 97\% homology with the amino- acid sequence of the corresponding region of RCP. DD2B contained the Rab-binding domain (RBD)-a $\mathrm{COOH}$ terminal predicted alpha helical coiled-coil domain. This is a conserved motif observed in all members of Rab11-FIPs (Rab11 family of interacting proteins) such as RCP, Rip 11, Rab11-FIP1, Rab11-FIP2, Rab11-FIP3 and Rab11FIP4. The DD2B cDNA fragment was characterized in detail for the present study.

\section{Validation of the DD2B fragment}

Labeled DD2B fragment was used to detect the presence of corresponding transcripts in RNA samples from human endometrium and peripheral blood leukocytes. Two transcripts of 6.0 and $4.0 \mathrm{~kb}$ were detected (Fig. 3A). Furthermore, a 219 bp RT-PGR product was detected with DD2B-specific primers in RNA samples from monkey testis, epididymis, placenta, ovary and endometrium (Fig. 3B). These results indicated that the gene corresponding to the DD2B fragment is expressed in a variety of tissues, and that it was neither a DDRT-PCR-generated artifact because of the residual genomic DNA contamination in RNA samples, nor a result of the amplification of some intronic sequences at the $3^{\prime}$ end.

\section{Characterization of the DD2B fragment}

To confirm that the DD2B fragment represents the $3^{\prime}$ region of the RGP gene, RT-PCR studies were carried out with a forward primer deduced from the $3^{\prime}$ region of RCP and a reverse primer derived from the DD2B fragment. An expected product of $776 \mathrm{bp}$ was obtained (Fig. 4). The specificity of the product was validated by two hemi-nested PCRs. One generated a product of $436 \mathrm{bp}$ when reamplified with primers deduced from the established sequence of RCP (Fig. 4A, lane 2). The other reaction generated a product of $219 \mathrm{bp}$ when the sequences deduced from DD2B were used for amplification (lane 1). Southern hybridization of these products with labeled DD2, as well as sequencing of $776 \mathrm{bp}$, proved that the DD2B fragment represented the RCP gene. The PCR product $(436 \mathrm{bp})$ obtained with both primers specific to RCP did not hybridize with labeled DD2 (Fig. 4B). The region spanned by $436 \mathrm{bp}$, though a part of RCP, did not include any of the sequences encompassed by DD2. Sequence analysis of the $776 \mathrm{bp}$ product revealed 95\% homology with the human RCP cDNA sequence (Accession no. AF 368294). The partial conceptual amino-acid sequence of the DD-RCP product, obtained with monkey samples, revealed differences at 14 positions when compared with the human RCP (Fig. 5). The partial monkey RCP nucleotide and conceptual protein sequences have been submitted to the gene bank (Accession no. AY 435038).

\section{Hormonal regulation of $\mathrm{RCP}$}

RT-PGR studies indicated a fourfold upregulation in the DD-RCP expression in proliferative-phase endometrium 

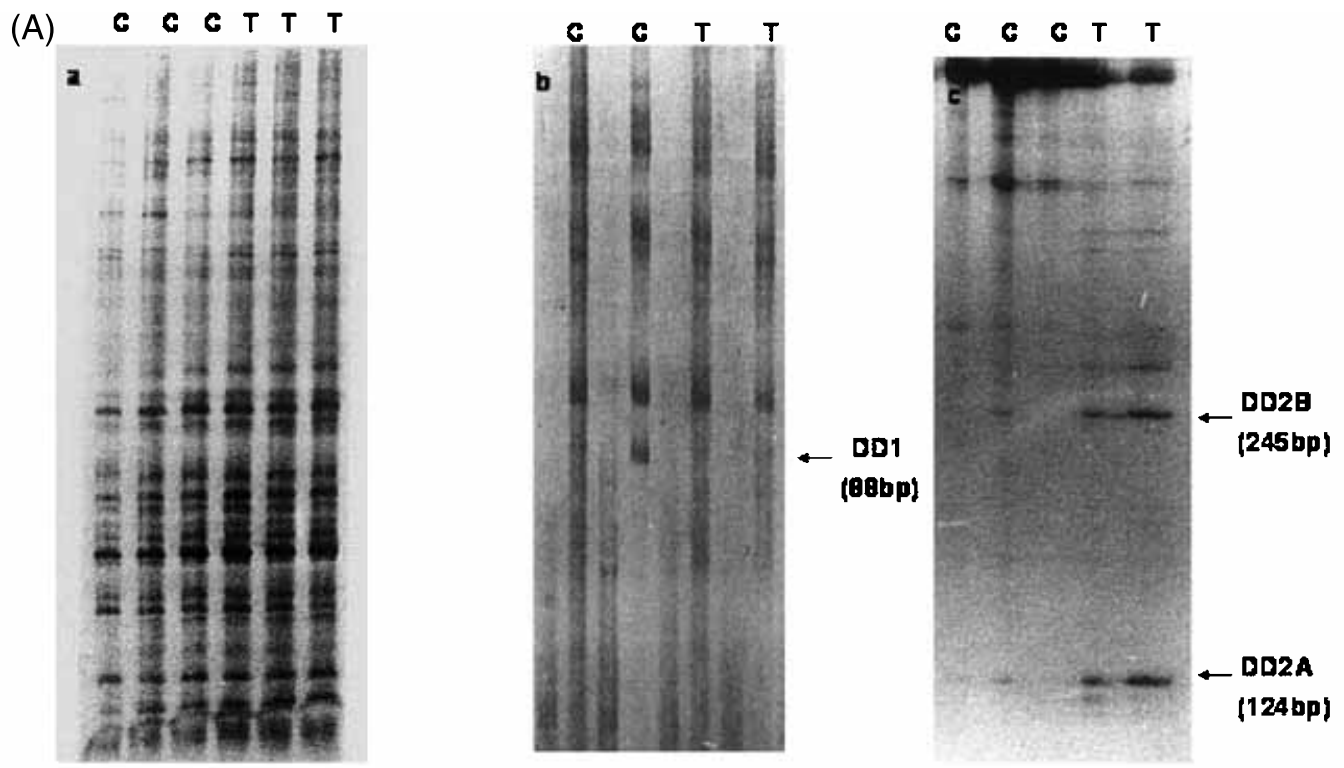

(B)
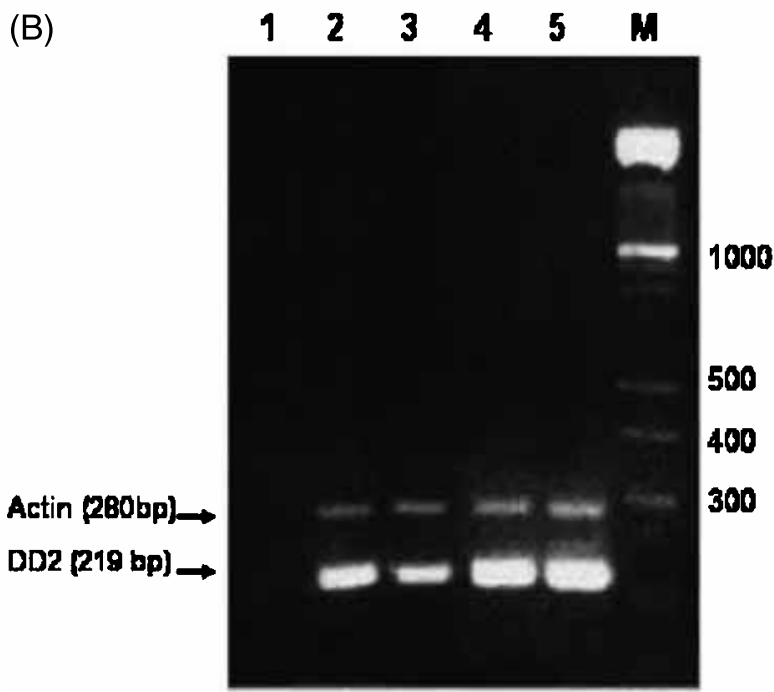

(C)

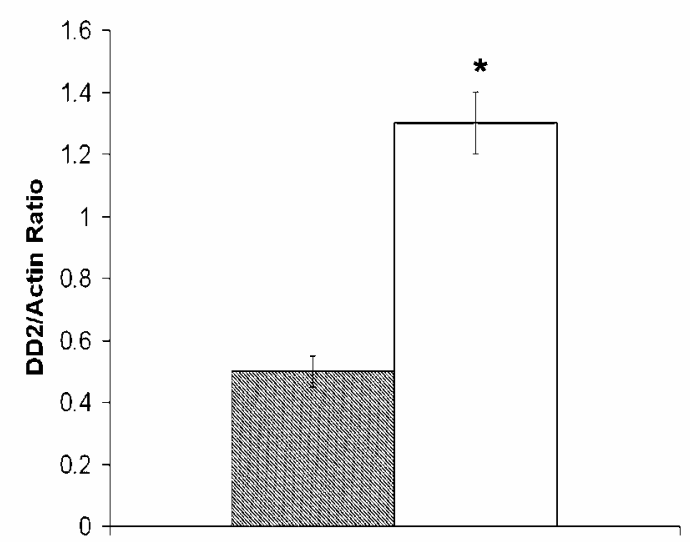

Figure 1 (A) Differential display (DD) reverse transcription-polymerase chain reaction (DD-RT-PCR) to identify differentially expressed cDNA fragments in peri-implantation-phase endometria from control $(C)$ and onapristone-treated animals ( $T$ ). ${ }^{33}$ P-labeled DD-RT-PCR products were run in $6 \%$ nondenaturing polyacrylamide gel electrophoresis and visualized by autoradiography. Panels a-c show only the sections of gels with representative results of experiments performed for all animals in each group. (a) Equal representation of all cDNA fragments in peri-implantation-phase endometria from C and T. Total RNA samples from $\mathrm{C}$ and $\mathrm{T}$ were reverse transcribed with anchored oligo dT primer (V3) and amplified with arbitrary primer (V10) and anchored oligo dT primer (V16). (b) Lower representation of DD1 cDNA fragment in peri-implantation-phase endometria from T. Total RNA samples from $C$ and $T$ were reverse transcribed with anchored oligo dT primer (V1) and amplified with arbitrary primer (V10) and anchored oligo dT primer (V16). (c) Higher representation of some cDNA fragments including DD2A and DD2B in peri-implantation-phase endometria from T. Total RNA samples from C and T were reverse transcribed with anchored oligo (V1) and amplified with arbitrary primer (GR1) and anchored oligo dT primer (V16). (B) Biplex RT-PCR analysis to compare the levels of DD2 transcripts in peri-implantation-phase endometrial RNA samples from control (lanes 2 and 3 ) and treated (lanes 4 and 5) animals. Agarose gel (2\%) was loaded with RT-PCR products and visualized by ethidium bromide staining. The reaction mixture without the RNA template is loaded in lane 1. Molecular size marker (100 bp ladder) is shown in lane M. The expression of DD2 transcripts was higher in the peri-implantation-phase endometria from treated animals than control animals, as revealed by the densitometric analysis of the intensities of DD2 and actin RT-PCR products for each sample and estimation of the ratios between DD2 and actin RT-PCR products (lower panel). Control indicates DD2/actin transcript ratio in peri-implantation-phase endometria from control animals; treated indicates the ratio in $5.0 \mathrm{mg}$ onapristone-treated animals. 
DD1

5'ATTGACCTCTAGATGCTGTTGTCCTGCCACTCCCTAGATAATTATAATAAATACTATG GAAACACAAAAAAAAAAAAAAGCTTCGCAA3

DD2A

5'ATTTACAACGAGGCCATGATGAAGAAATACAGCCCCTCAGACCCTGCATTTGCGTA CGCACAGCTGACCCATGATGAGCTCATCCAGCTGGTCCTCAAACAAAAAAAAAAAAA AGGCTTCGAA3'

DD2B

5'ATTTACAAGGAGGCGATGATGAAGAAATACAGCCCCTCAGACCCTGCATTTGCGTA CECACAGCTGACCCATGATGAGCTCATCCAGCTGGTCCECAAACAGAAGGAAACGAT AAGCAAGAAGGAGTTCCAGGTCCGAGAGCTGGAAGACTACATTGACAACCTGCTTGT CTGAGTCATGGAAGAAACCCCCAATATCCTCCGCATCCCGACTCAGGTTGACAAAAA AAAAAAAAAGCTTCGCAA3

Figure 2 cDNA sequences of DD1, DD2A and DD2B (DD2) fragments.
(Fig. 6A, lanes 1 and 2) as compared with periimplantation-phase endometrium in control animals (lanes 3 and 4). The expression levels of DD-RCP transcripts were not significantly different between the peri-implantation-phase endometria from control and $2.5 \mathrm{mg}$ onapristone-treated animals (lanes 5 and 6). However, a significant increase $(P<0 \cdot 05)$ was seen in this expression in the endometria from $5.0 \mathrm{mg}$-treated animals (lanes 7 and 8). These results suggest that the endometrial expression of the RCP gene is regulated in a cycle-dependent manner. It also indicates that RCP expression is repressed during the peri-implantationphase, that is, in the presence of high progesterone levels during receptive conditions (Fig. 6B). In situ localization studies performed with a DD2B probe also corroborated these results. RGP transcripts could be localized in

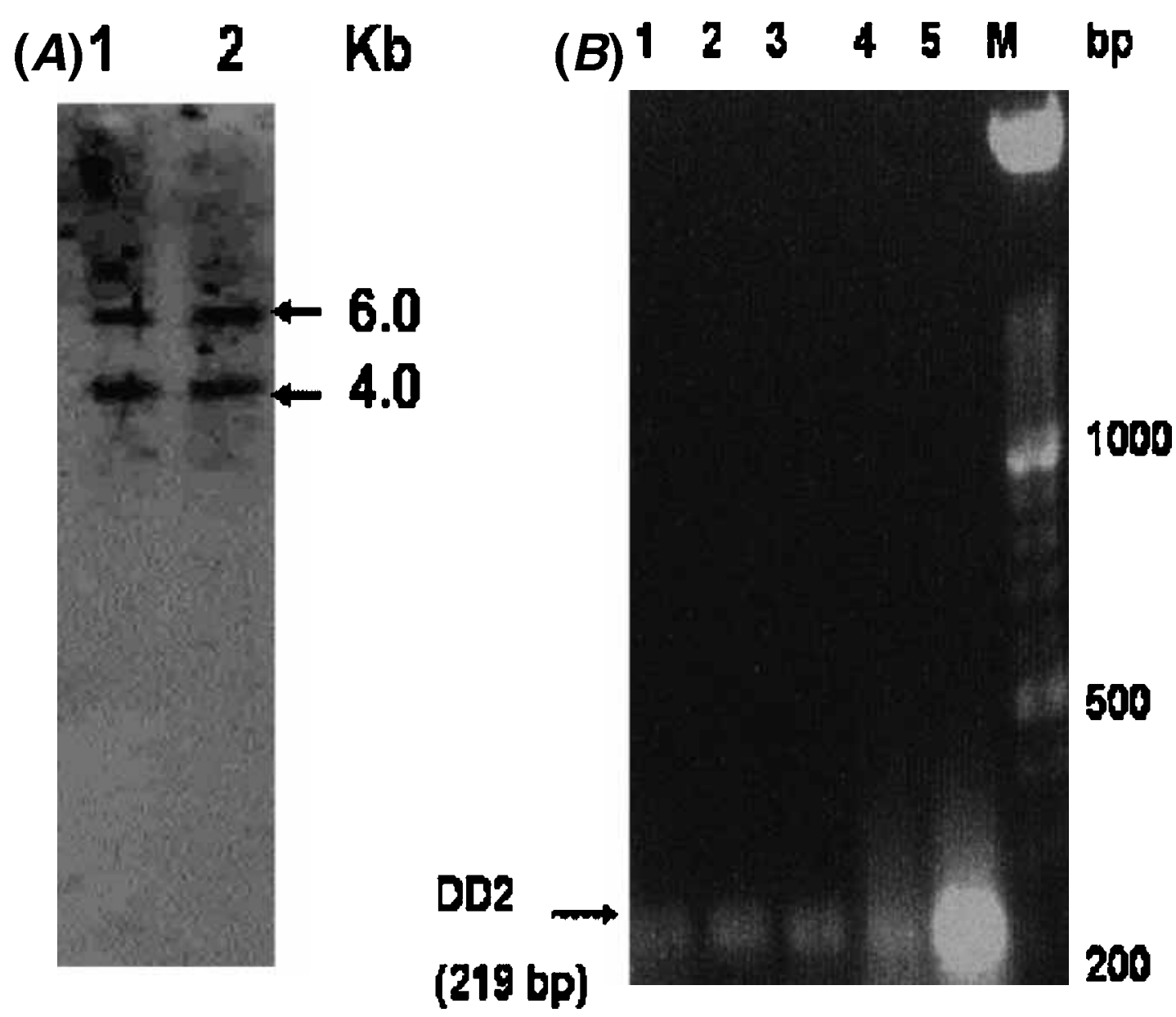

Figure 3 (A) Northern blot analysis with digoxigenin-labeled DD2B fragment to detect the corresponding full-length transcripts in total RNA samples from human endometrium (lane 1) and peripheral blood lymphocytes (lane 2). Two transcripts of 6.0 and $4.0 \mathrm{~kb}$ were detected by chemiluminescence after nonradioactive hybridization. (B) RT-PCR analysis to detect the expression of DD2 fragment in monkey tissues, that is, placenta (lane 1), epididymis (lane 2), testis (lane 3), ovary (lane 4) and endometrium (lane 5). Molecular size markers (100 bp ladder) were loaded in lane M. A RT-PCR product of $219 \mathrm{bp}$ was obtained with primers DD2.1 and DD2.2 deduced from DD2 sequence. 

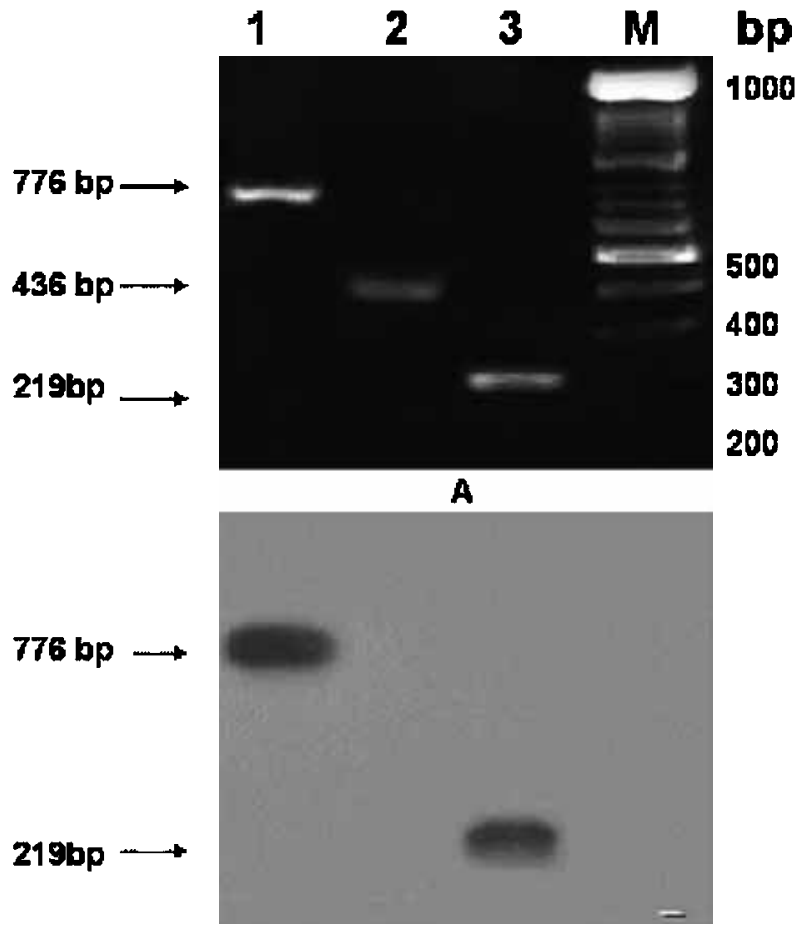

B

Figure 4 Validation of DD2 cDNA fragment to demonstrate its identity as Rab-coupling protein (RCP). (A) A forward primer from RCP (RCP1) and reverse primer from DD2 (DD2.2) in RTPCR reaction amplified a product of $776 \mathrm{bp}$ in total RNA samples from monkey peri-implantation-phase endometrium (lane 1). An aliquot of $776 \mathrm{bp}$ RT-PCR product was subjected to hemi-nested PCR, using either RCP1 and RCP2 as forward and reverse primers respectively (lane 2 ) or DD2.1 and DD2.2 as forward and reverse primers respectively (lane 3 ). PCR products of $436 \mathrm{bp}$ (lane 2) and $219 \mathrm{bp}$ (lane 3) were obtained. Lane $\mathrm{M}$ is loaded with the $100 \mathrm{bp}$ molecular size marker. (B) Southern blot analysis of the above products probed with digoxigenin-labeled DD2 cDNA fragment.

nuclei as well as in cytoplasm of glandular epithelial and stromal cells of the endometrium (Fig. 7). The transcripts were localized in functionalis and basalis zones of the endometrium. These results suggest that RCP localization is not restricted to the specific zones of endometrium. Localization of endometrial RCP transcripts was higher in the proliferative phase than in the periimplantation phase in control animals (Fig. 7B and C). Furthermore, this localization in peri-implantationphase endometria was significantly $(P<0 \cdot 05)$ higher in treated animals than in control animals (Fig. 7C). This difference was more marked for the RCP localization in the glandular epithelium compartment. Similar results were obtained when DD-RCP was used as a probe to localize the transcripts (data not shown). To determine whether in vivo progesterone insufficiency results in similar changes to those observed in the antiprogestin- treated animals, endometrial RCP expression during the peri-implantation phase was analyzed in luteal-phaseinsufficient animals (circulating progesterone levels less than $2 \mathrm{ng} / \mathrm{ml}$ ). Endometrial RCP transcripts levels were found to be twofold higher in luteal insufficient animals than control animals (data not shown). This indicates that suboptimal progesterone levels or action modulates the transcription of endometrial RCP.

\section{Endometrial Rab4 and Rab11 expression}

Peri-implantation-phase endometrial sections from control and antiprogestin-treated animals were immunostained for the localization of Rab4 and Rab11. These were found to be localized more intensely in the perinuclear region in the glandular epithelium of periimplantation-phase endometria from control animals. Interestingly, in treated animals, Rab4 localization was predominant in the cytoplasmic compartment of glandular epithelium (Fig. 8). However, Rab4 and Rab11 did not show any significant increase in the intensity of immunostaining in endometrial glandular epithelium or stromal compartments in treated animals as compared with control animals.

\section{Endometrial RCP expression in humans}

When compared within the control group, endometrial RCP expression was significantly higher $(P<0 \cdot 01)$ in late luteal and proliferative phases than in peri-implantationphase human biopsies (Fig. 9A). Furthermore, endometrial RCP expression during the peri-implantation phase in infertile women $(n=3)$ was significantly $(P<0 \cdot 05)$ higher than that in fertile women $(n=3)$ (Fig. 9B). These findings indicate that the pattern of endometrial RCP expression is similar to that observed in monkey endometrium, that is, low during the peri-implantation phase and high during the proliferative phase of the cycle.

\section{In vitro expression of RCP in human endometrial explants}

Real-time PCR analysis did not show any significant change in RCP transcript levels after estradiol or progesterone treatment of short-term human endometrial explants. Mean Ct values for DD2 or RGP were $23 \cdot 11 \pm 0 \cdot 05,23 \cdot 74 \pm 0 \cdot 02$ and $23 \cdot 05 \pm 0 \cdot 6$ for control, estradiol-treated and progesterone-treated explants respectively, whereas the respective mean $\mathrm{Ct}$ values for $18 \mathrm{~S}$ rRNA were $10 \cdot 47 \pm 0 \cdot 02,11 \cdot 06 \pm 0.06$ and $11 \cdot 57 \pm 0 \cdot 10$ for control, estradiol-treated and progesterone-treated explants respectively. PCR efficiencies were 1.8 and 1.78 for the standard curves generated for $18 \mathrm{~S}$ rRNA and DD2 respectively. The expression ratio was 0.98 when DD2 expression in control and estradiol-stimulated explants was compared, and it was 


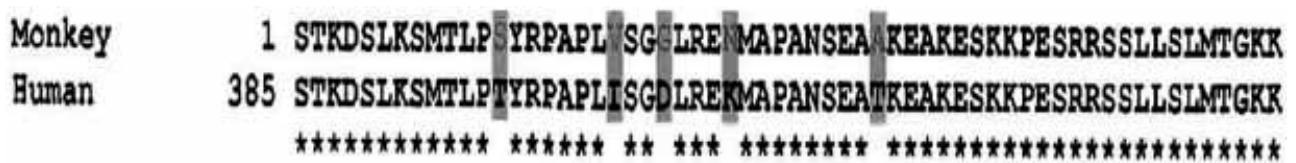

\begin{tabular}{|c|c|}
\hline Monkey & 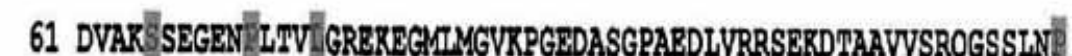 \\
\hline Human & 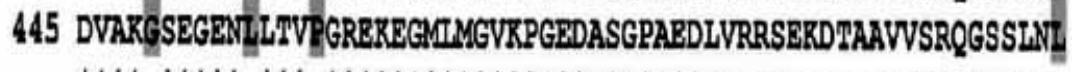 \\
\hline
\end{tabular}

\begin{tabular}{|c|c|}
\hline Monkey & IEDVQITEPEAEPESKSEP PPISS RAPQIRAV \\
\hline Human & 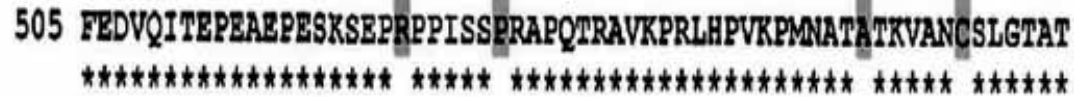 \\
\hline
\end{tabular}

\begin{tabular}{|c|c|}
\hline Monkey & 181 IISENLNNEAMMKKYSPSDPAFAYAQLIYDELIQLVLRQKBTI SKKEEQVRBLEDYIDNZ \\
\hline Buman &  \\
\hline
\end{tabular}

\begin{tabular}{|c|c|}
\hline Monkey & 241 LVRWEETPNILRIPMQV \\
\hline Human & 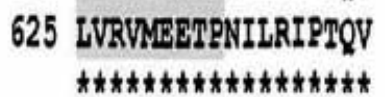 \\
\hline
\end{tabular}

Figure 5 Predicted amino-acid sequences of human and monkey RCP partial cDNA sequences. The amino-acid mismatches (highlighted) are outside the Rab-binding domain (the highlighted stretch of aminoacid regions 231-249 in monkey RCP and 615-633 in human RCP).

1.006 for comparison of DD2 expression in control and progesterone-stimulated cultures. Some of these human explants that did not show any change in the levels of RCP transcripts after supplementation with estradiol and progesterone were also investigated for the immunolocalization of estradiol receptor and cyclooxygenase-2, proteins known to be regulated by estradiol and progesterone respectively. An increase was observed in the immunolocalization of these proteins (data not shown), thereby indicating the ability of the explants to respond to exogenous hormones.

\section{Expression of endometrial steroid receptors}

No significant changes were observed in the levels of transcripts for steroid receptors, that is, estrogen receptor and progesterone receptor, in the animals showing increased expression of RCP after antiprogestin treatment. We observed a similar pattern at the levels of immunoreactive steroid receptor proteins also. These observations suggest that the upregulation in endometrial RCP is not associated with any perturbation in the levels of steroid receptor transcripts, and that steroid receptors and RCP are not coregulated (Fig. 10). These studies also indirectly ruled out the direct effect of estrogenic influences after progesterone neutralization on endometrial RCP expression.

\section{Discussion}

In the present study, we employed DD-RT-PCR to identify the genes that are either directly or indirectly regulated by progesterone and are of potential relevance to endometrial receptivity under in vivo conditions. We considered it logical to scan randomly the entire expression profiles of receptive and nonreceptive endometria, rather than predefining the range of targets, as done especially in low-density microarrays. Some gene fragments that have never been identified in endometrium or investigated for their potential role in endometrial function were characterized in detail for the present study.

DD-RT-PCR analysis revealed several cDNA fragments that did not show any change in their expression patterns in peri-implantation-phase endometria from 

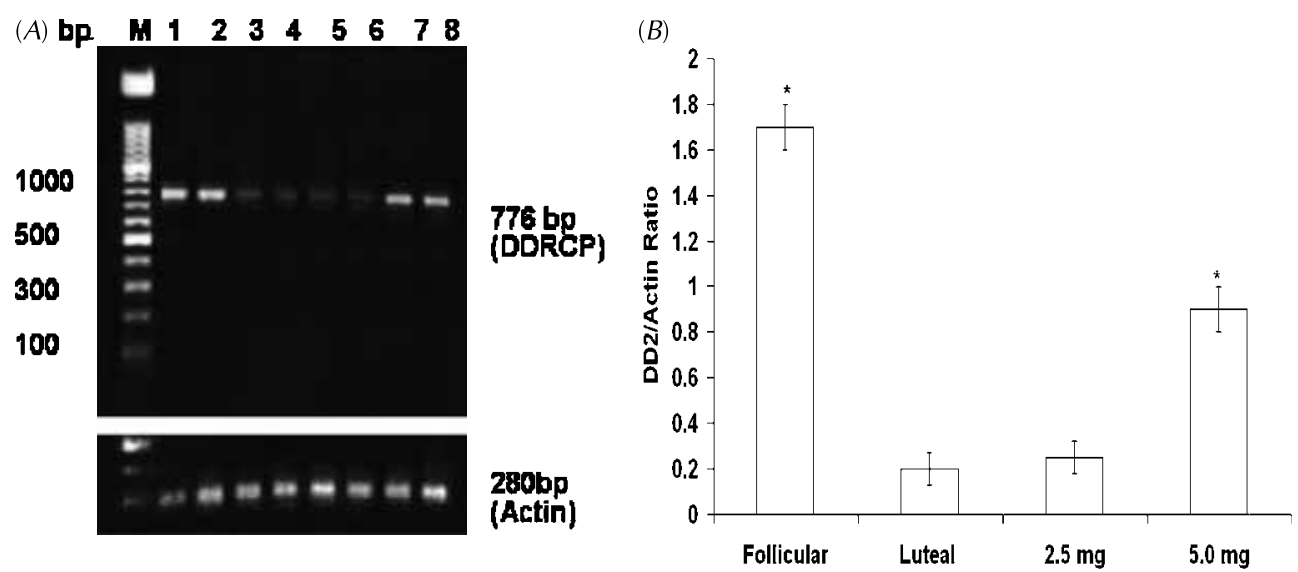

Figure $6(A)$ Hormonal regulation of endometrial RCP expression as assessed by RT-PCR analysis using gene-specific primers. Agarose gel (1\%) was loaded with RT-PCR products obtained with endometrial RNA samples from control animals in proliferative phase (lanes 1 and 2) and peri-implantation phase (lanes 3 and 4), and from treated animals (2.5 mg: lanes 5 and 6; $5.0 \mathrm{mg}$ : lanes 7 and 8) in peri-implantation phase. A significantly higher level of RCP expression was observed in proliferative-phase endometria from control animals and also in peri-implantation-phase endometria from $5.0 \mathrm{mg}$-treated animals. RNA samples were normalized for $\beta$ actin expression (lower panel). (B) The endometrial expression of RCP during follicular phase, during Luteal phase in control, $2.5 \mathrm{mg}$ treated- and $5.0 \mathrm{mg}$-treated (d) animals. The intensities of RT-PCR products for DDRCP and $\beta$ actin, as visualized in agarose gel, were quantitated by Gel Pro software and expressed as IODs (integrated optical density). The ratios of IODs for DDRCP and $\beta$ actin for each animal in each group were calculated. The mean IOD \pm S.E.M. for each group is shown. Endometrial RCP expression in each group was compared with that in the peri-implantation-phase endometrium of control animals. *Indicates the level of statistical significance $(P<0.05)$.

control and antiprogestin-treated animals. Our previous studies had also indicated the equivalent expression of $\beta$ actin and epidermal growth factor receptor transcripts in receptive and nonreceptive endometria (Sachdeva et al. 2001). Apparently, these genes are not regulated by progesterone at the transcriptional level. It may also be inferred that at the selected dosages antiprogestins act on specific genes. Use of a different set of arbitrary primers and anchored oligo dT primers in DD-RT-PGRs, however, revealed lower representation of some endometrial cDNA fragments in treated animals than in control animals. Sequence analysis of one of these fragments (DD1) showed its similarity with a region in a MHC BAC clone from rhesus monkey (M. mulatta). MHC molecules, which are known to play a significant role in immune rejection responses, have been found to be expressed by endometrial epithelial cells also (Semino et al. 1995, Wallace et al. 2001). Interestingly, Kao et al. (2002) demonstrated lower levels of MHC transcripts in receptive endometrium than in prereceptive endometrium. However, we observed a higher representation of DD1 in receptive endometria than in nonreceptive endometria from bonnet monkeys. These discrepant findings could arise from differences in the experimental approaches, study design and study subjects employed in these two studies.

In contrast to DD1, DD2A and DD2B cDNA fragments were found to be highly represented in nonreceptive endometrium. The homology of DD2B with RCP, a recently discovered protein implicated in intracellular vesicular trafficking (Lindsay et al. 2002), prompted us to investigate this gene fragment in detail. Ours is the first report to demonstrate the expression of RCP in primate endometrium. Intracellular vesicular trafficking mediates the transport of transmemberane proteins, secretory proteins and cell-surface proteins from one membrane compartment to another (Egea 2001). These events are known to be regulated by a number of proteins, including Rab GTPases or Rab proteins (Bock et al. 2001). The vesicle transport of each cellular organelle is mediated via a specific Rab protein, localized in that organelle. For example, Rab1, 2 and 6 have been localized at the endoplasmic reticulum and Golgi apparatus (Bock et al. 2001), whereas Rab4 and 5, located on early endosomes, control early steps of the endocytic process, and mediate endosome endosome fusion and receptor recycling (Van der Sluijs et al. 1992, Stenmark et al. 1994). Rab1 1, localized to the endosomal recycling compartment and trans-Golgi network (TGN), has been shown to regulate the targeting of transport vesicle to the plasma membrane and also the trafficking between the endosomal compartment and the TGN (Urbe et al. 1993, Ullrich et al. 1996, Wilcke et al. 2000). Interestingly, Rabl1 has been found to be induced by estrogen in rats. It has been proposed that Rab11 may regulate secretory activities that are critical for blastocyst 


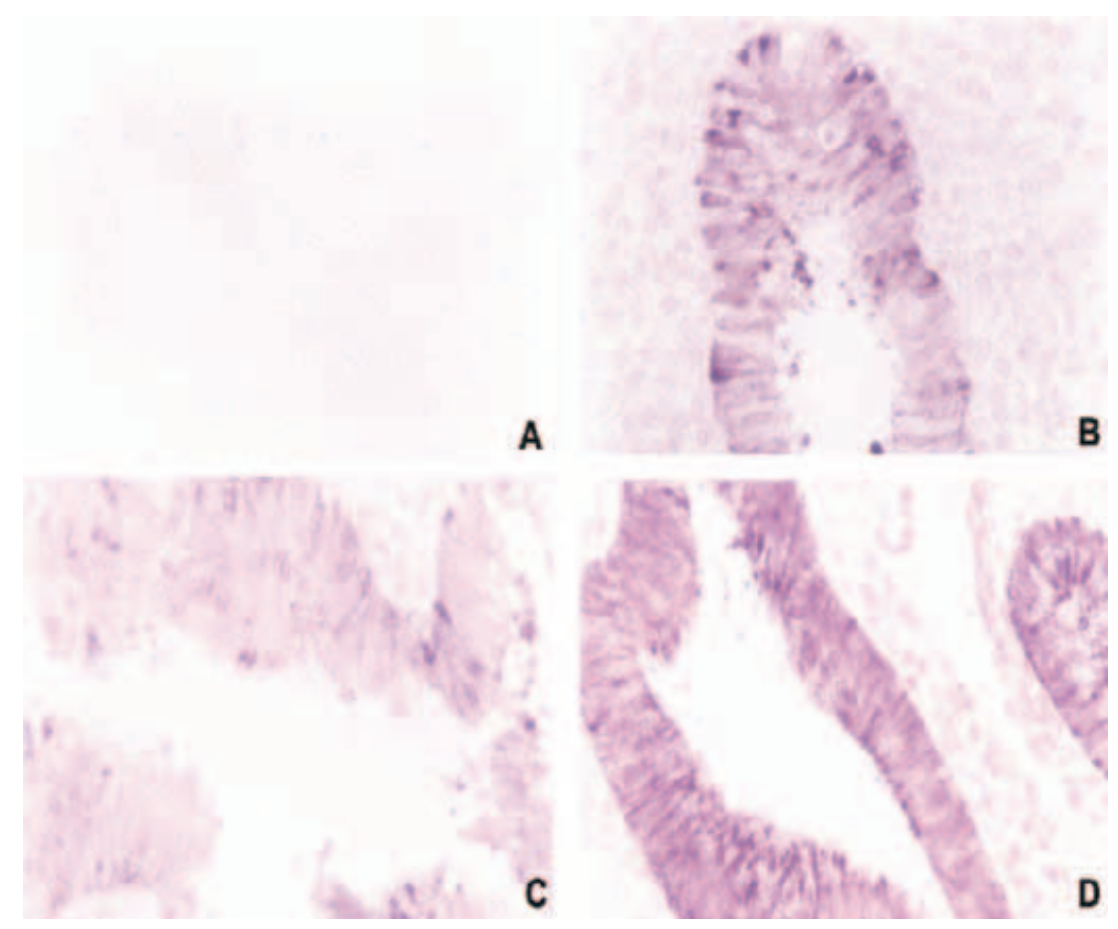

Figure 7 In situ localization of RCP transcripts using labeled DD2 cDNA in proliferative-phase $(B)$ and peri-implantation-phase $(C)$ endometria from control animals and also in the peri-implantation-phase endometria from animals treated with $5.0 \mathrm{mg}$ onapristone (D). (A) Negative control section. Note the intense localization of $\mathrm{RCP}$ transcripts in the glands of proliferative-phase endometrium and the drastic drop in expression in the peri-implantation-phase endometria in control animals.

Onapristone treatment upregulated the expression of RCP mRNA predominantly in the endometrial glands. $\times 200$.

implantation (Chen et al. 1999). At present, Chen et al.'s is the only report to suggest hormonal regulation of intracellular trafficking in the uterus.

It is estimated that each Rab protein may have up to 20 different cellular effectors (Hales et al. 2001). RCP, a gene found to be upregulated in nonreceptive endometrium in the present study, is a recently discovered member of the Rabl1 family of interacting proteins (Rab11-FIPs) (Lindsay et al. 2002). However, it exhibits low overall homology with the other members of Rab11-FIPs, that is, Rab11-FIP1, Rab11-FIP2, Rab11FIP3, Rip-11 and Rab11-FIP4. RCP, localized to the early endosomal recycling compartment, consists of two functional and well-conserved domains: a helical coiledcoil domain at its carboxyl terminus that encompasses the Rab-binding domain (RBD) and either a $\mathrm{C} 2$ or EF hand domain in the amino terminal region (Hales et al. 2001, Prekeris et al. 2001).

In the present study, the expression of endometrial RCP transcripts in human and bonnet monkeys was found to be cycle dependent; that is, high in the proliferative phase and low in the peri-implantation phase. In animals with luteal insufficiency and during late luteal phase in control women, RCP expression was found to be higher. This suggests that progesterone either directly or indirectly suppresses RCP transcription. To our surprise, RCP was not identified as one of the differentially expressed genes in microarray analysis of the proliferative-phase and peri-implantation-phase human endometria (Kao et al. 2002). The inability to detect the differential expression of RCP in these studies may be attributed to either the potential nonexistence of RCP as one of the targets on commercial chips or the use of pooled human samples with variations in the levels of RCP transcripts. Northern blot analysis using digoxigenin-labeled DD2 or DD-RCP revealed two transcripts of approximately 6.0 and $4.0 \mathrm{~kb}$ in total RNA samples from human endometrium and peripheral blood lymphocytes. DD2 transcripts were also detected in monkey ovary, testis, epididymis, and placenta by RT-PCR. These results agreed with the previous observation, suggesting that the RCP is expressed in the majority of tissues, including brain, heart, testis, lung, spleen, ovary, small intestine and liver (Lindsay et al. 2002). Detection of two fragments, DD2A and DD2B, which shared identical sequences except for the presence 

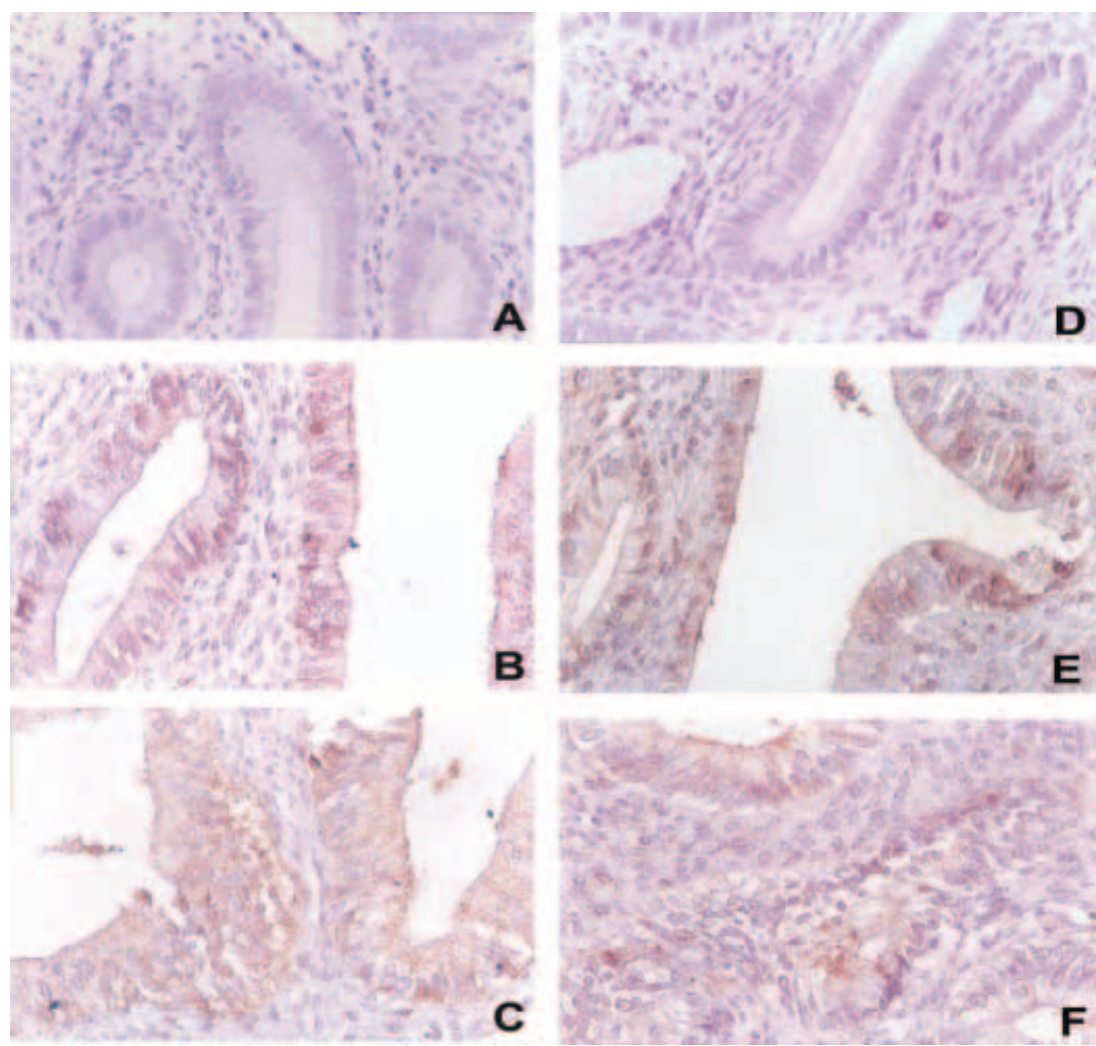

Figure 8 Immunolocalization of Rab4 (A-C) and Rab11 (D-F) in the peri-implantation-phase biopsies from control (B and $\mathrm{E})$ and $5.0 \mathrm{mg}$ onapristone-treated ( $\mathrm{C}$ and $\mathrm{F}$ ) animals. Respective negative controls (without primary antibodies) are shown in A and D. Glandular epithelium showed more staining for both antigens than stroma. $\times 200$.

of an additional 120 bases at the $3^{\prime}$ end in DD2B indicated the possibility of alternate splicing of the RCP gene. Northern analysis also detected two transcripts. However, Lindsey et al. (2002) detected a single band of $80 \mathrm{kDa}$ for RCP protein in the cell lysates of placental trophoblastic choriocarcinoma, premyelocytic monocytes, epidermoid carcinoma and cervical carcinoma. At present, there are no published data on the molecular size of RCP transcripts or its splice variants. We detected similar-sized transcripts in RNA from peripheral blood lymphocytes also. It is likely that the RCP transcripts of 6.0 and $4.0 \mathrm{~kb}$ contain some untranslated sequences, which are eventually processed through post-transcriptional modifications to encode an $80 \mathrm{kDa}$ protein.

The overexpression of a dominant negative mutant of RCP that contains RBD has been shown to inhibit the recycling of transferrin to the membrane of cells expressing the mutant. It has been proposed that excess of RCP may sequester endogenous Rab1 1 and/or Rab4 in an inactive complex (Lindsay et al. 2002). It is likely that the similar overexpression of RCP in nonreceptive endometrium, as observed in the present study, might result in sequestering of Rab4 and Rab11, thus making them unavailable for some critical membrane trafficking events required for endometrial receptivity. Interestingly, there was no significant change in the levels of immunoreactive Rab4 or Rab11 in nonreceptive endometrium from antiprogestin-treated animals.

It is now becoming apparent that more genes are downregulated than upregulated in secretory endometrium (Kao et al. 2002, Ace \& Okulicz 2004). Downregulation of RGP expression during the midsecretory phase in control animals, as observed in the present study, corroborates this pattern. It may be speculated that this is due to a combination of both loss of estradiol action and direct or indirect downregulation of genes by progesterone in the secretory phase (Ace \& Okulicz 2004). However, in vitro endometrial explants cultured for a short term in the presence of progesterone or estradiol did not show any significant change in the levels of RCP transcripts in the present study. Furthermore, the upregulation in endometrial RCP expression after antiprogestin treatment was found to be dose 

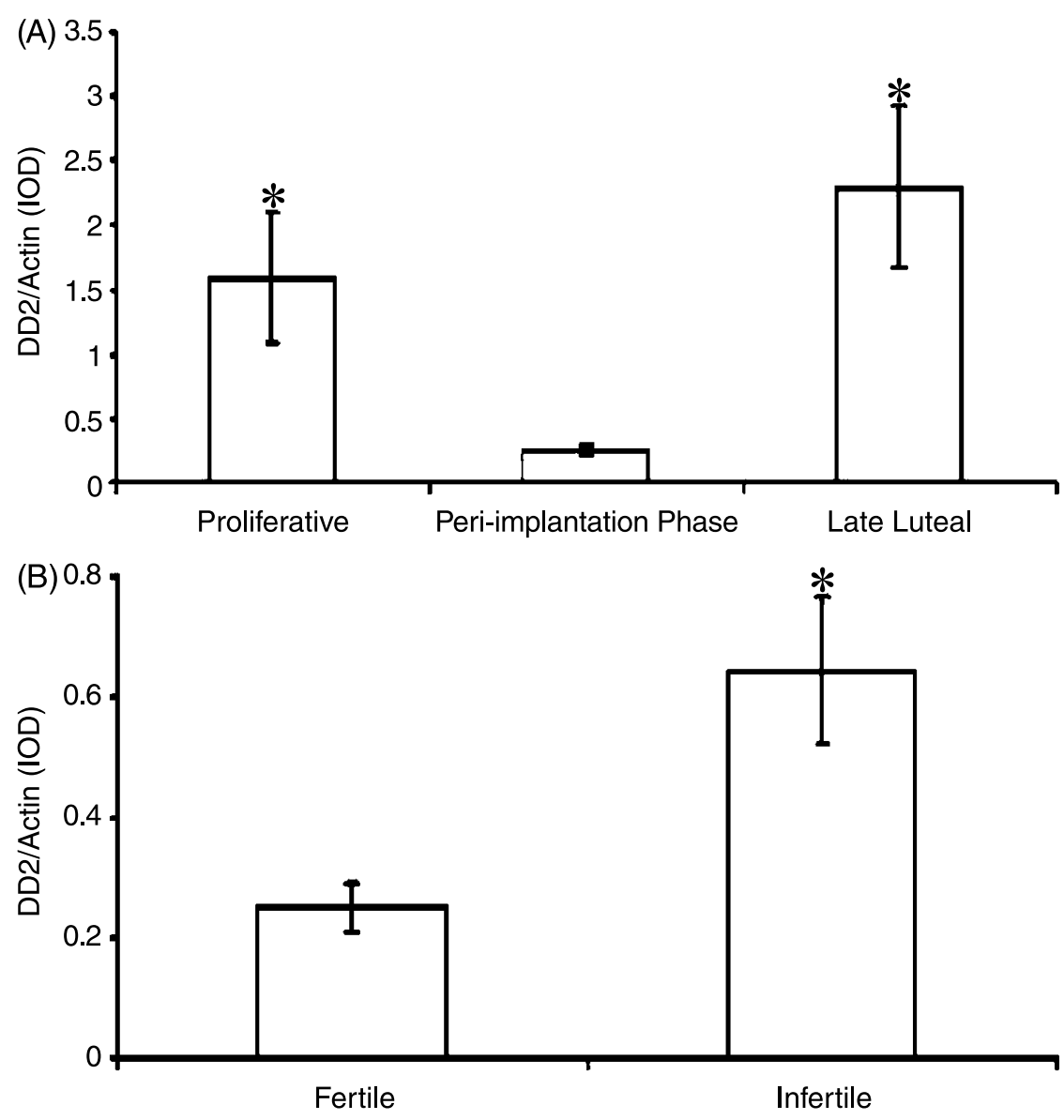

Figure 9 ( A) Endometrial expression of DD2 during different phases of the menstrual cycle in fertile women. The intensities of RT-PCR products for DD2 and $\beta$ actin, as visualized in agarose gel, were quantitated by Gel Pro software and expressed as IOD (integrated optical density). The ratios of IODs for DD2 and $\beta$ actin for each case in each group were calculated. The mean IOD \pm S.E.M. for each group ( $n=3$ in each) is shown. The levels of endometrial DD2 transcripts were significantly less during the peri-implantation phase than other phases in fertile women. *Indicates the level of statistical significance $(P<0.01)$. (B) Endometrial expression of DD2 during peri-implantation phase in fertile and infertile women. The intensities of RT-PCR products for DD2 and $\beta$ actin, as visualized in agarose gel, were quantitated by Gel Pro software and expressed as IOD. The ratios of IOD for DD2 and $\beta$ actin for each case in each group ( $n=3$ in each) were calculated. The mean IOD \pm S.E.M. for each group is shown. The levels of endometrial DD2 were significantly higher in infertile than fertile women during the peri-implantation phase. *Indicates the level of statistical significance $(P<0.05)$.

dependent. This reinforces that progesterone may not act directly on RCP to inhibit its transcription. Although in silico analysis of available human RCP gene sequence did reveal the presence of PRE and ERE elements, their in vivo or in vitro potency to modulate the RCP expression in response to steroids is not known, especially in the context of cellular environment. It is more likely that the progesterone-dependent repression of RCP transcription requires involvement of some unidentified transrepressors that are probably either activated by progesterone or inactivated by estradiol in vivo.

To determine whether the enhanced expression of endometrial RCP is associated with a change in progesterone receptor (PR) and estradiol receptor (ER) levels, we analyzed their transcript levels in receptive and nonreceptive endometria. There was no significant change in the levels of these receptors. This also suggested that endometrial steroid receptors and RCP are not coregulated and that the increase in RCP expression in nonreceptive endometrium may not be a direct outcome of potential estrogenic influences, triggered by progesterone neutralization. Since treated animals did not show any change in circulatory estradiol levels or endometrial estradiol receptor levels, as compared with control animals, it seems more likely that it is progesterone that indirectly represses the RCP transcription in vivo during the receptivity period.

The present study demonstrates the endometrial expression of RCP, a novel protein implicated in intracellular vesicular trafficking and its differential expression in receptive and nonreceptive endometrium in primates. The study opens up exciting avenues for investigating the hormonal regulation of subcellular events in primate endometrium. Such investigations may provide interesting insights into the mechanism of endometrial receptivity in primates and may also lead to identification of endometrial factors contributing to infertility in humans.

\section{Acknowledgements}

We thank Dr Pervin Meherji, Deputy Director, NIRRH, for providing endometrial aspirates from fertile and infertile women, and Dr Usha Natraj (Former 


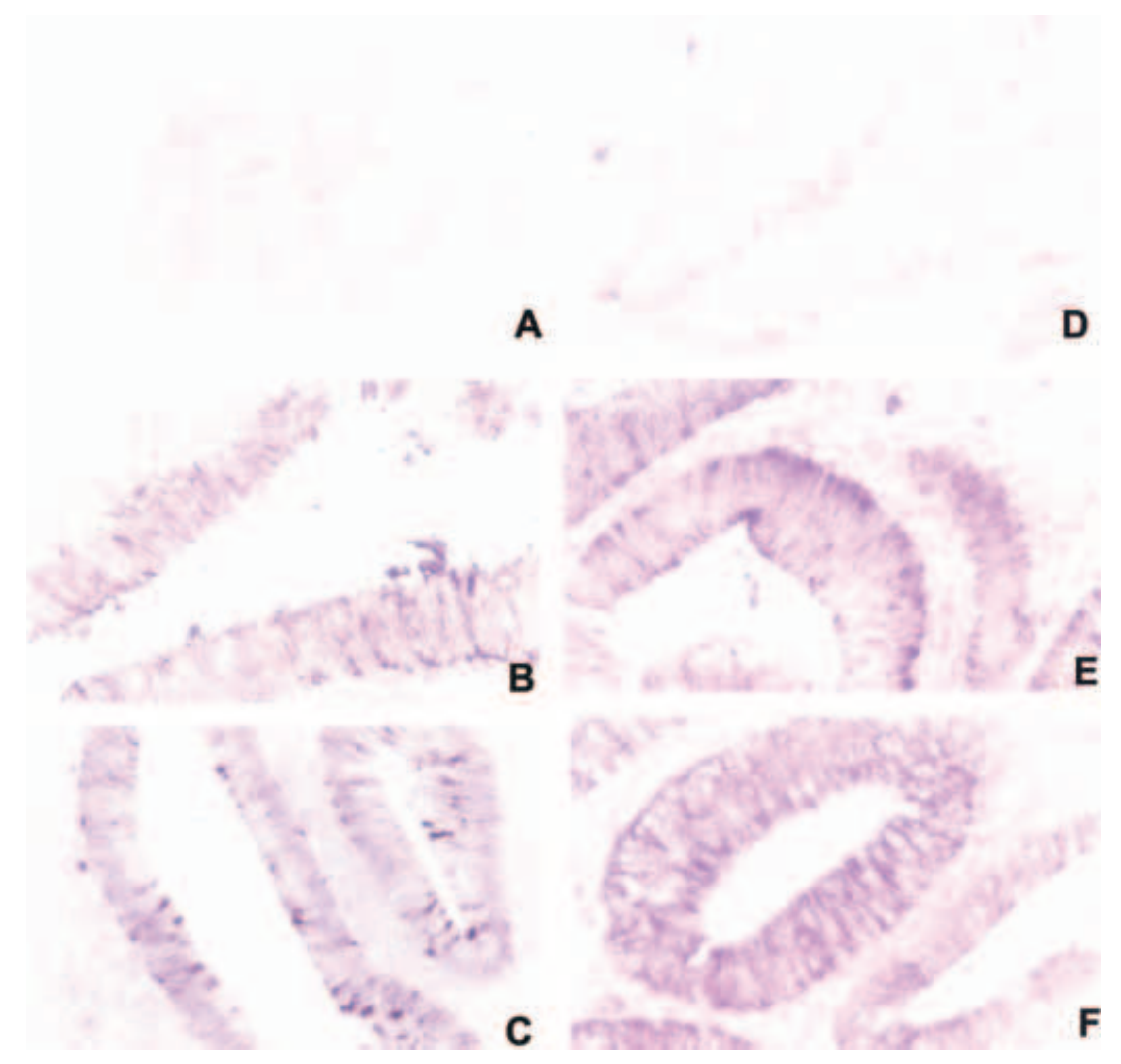

Figure 10 In situ localization of estrogen receptor $(A-C)$ and progesterone receptor $(\mathrm{D}-\mathrm{F})$ transcripts in the peri-implantation-phase endometria from control (B and $\mathrm{E})$ and $5.0 \mathrm{mg}$ onapristone-treated animals ( $C$ and $\mathrm{F}$ ). Sections hybridized with the respective sense probes are shown in $A$ and $D$. There was no significant change in the levels of transcripts for estrogen receptor and progesterone receptor in nonreceptive endometria from treated animals. $\times 200$.

Deputy Director, NIRRH) for her encouragement and support. We greatly appreciate the artwork done by $\mathrm{Mr}$ Hemant Karekar, and we also thank Ms Sushama Gadkar-Sable and Ms Gracy Rosario for their valuable help in immunohistochemical studies. The authors declare that there is no conflict of interest that would prejudice the impartiality of this scientific work.

\section{Funding}

This study was supported by the Indo-US Programme on Contraception and Reproductive Health Research, jointly funded by the Department of Biotechnology (DBT), the government of India and the National Institutes of Health, USA. We thank the Indian Council of Medical Research for financial support. We appreciate the financial support given to V S P by the Council of Scientific and Industrial Research (India).

\section{References}

Ace CI \& Okulicz WG 1995 Differential gene regulation by estrogen and progesterone in the primate endometrium. Molecular and Cellular Endocrinology 30 95-103.

Ace CI \& Okulicz WC 1999 Identification of progesterone dependent messenger ribonucleic acid regulatory patterns in the rhesus monkey endometrium by differential display reverse transcription polymerase chain reaction. Biology of Reproduction $\mathbf{6 0}$ $1029-1035$.

Ace CI \& Okulicz WC 2004 Micro array profiling of progesterone regulated endometrial genes during the rhesus monkey secretory phase. Reproductive Biology and Endocrinology 254.

Albrecht ED \& Pepe GJ 2003 Steroid hormone regulation of angiogenesis in the primate endometrium. Frontiers in Biosciences 8 416-429.

Albrecht ED, Babischkin JS, Lidor Y, Anderson LD, Udoff LC \& Pepe GJ 2003 Effect of estrogen on angiogenesis in co-cultures of human endometrial cells and microvascular endothelial cells. Human Reproduction 18 2039-2047.

Bock JB, Matein HT, Peden AA \& Scheller RH 2001 A genomic perspective on membrane compartment organization. Nature $\mathbf{4 0 9}$ 839-841. 
Catalano RO, Yanaihara A, Evans AL, Rocha D, Prentice A, Saidi S, Print CG, Charnock-Jones DS, Sharkey AM \& Smith SK 2003 The effects of RU486 on the gene expression profile in an endometrial explant model. Molecular Human Reproduction 9 465-473.

Chen D, Ganapathy P, Zhu LJ, Xu X, Li Q, Bagchi IC \& Bagchi MK 1999 Potential regulation of membrane trafficking by estrogen receptor alpha via induction of Rabll in uterine glands during implantation. Molecular Endocrinology 13 993-1004.

Egea G 2001 Train trip into the cell: the Golgi apparatus as the central station of the intracellular membrane traffic. Ciencia al DiA International 4 1-20.

Fazleabas AT, Kim JJ, Srinivasan S, Donnelly KM, Brudney A \& Jeffe RC 1999 Implantation in the baboon: endometrial responses. Seminars in Reproductive Endocrinology 17 257-265.

Giudice LC 2003 Elucidating endometrial function in the postgenomic era. Reproduction Update 9 223-235.

Haendler B, Yamanouchi H, Lessey BA, Chwalisz K \& HessStumpp H 2004 Cycle dependent endometrial expression and hormonal regulation of the fibulin-1 gene. Molecular Reproduction and Development 68 279-287.

Hales CM, Griner R, Hobdy-Henderson KC, Dorn MC, Hardy D, Kumar R, Navarre J, Chan EK, Lapierre LA \& Goldenring JR 2001 Identification and characterization of a family of Rab11interacting proteins. Fournal of Biological Chemistry 276 39067-39075.

Horcajadas JA, Riesewijk A, Martin J, Cervero A, Mosselman S, Pellicer A \& Simon C 2004 Global gene expression profiling of human endometrial receptivity. Fournal of Reproductive Immunology 63 41-49.

Ishwad PC, Katkam RR, Hinduja IN, Chawlisz S, Elger WAG \& Puri CP 1993 Treatment with a progesterone antagonist ZK 98.299 delays endometrial development without blocking ovulation in bonnet monkeys. Contraception 48 57-703.

Katkam RR, Gopalkrishnan K, Chawlisz S, Schillinger E \& Puri CP 1995 Onapristone (ZK 98.299): a potential antiprogestin for endometrial contraception. American Fournal of Obstetrics and Gynecology 173 779-787.

Kao LC, Tulac S, Lobo S, Imani B, Yang JP, Germeyer A, Osteen K, Taylor RN, Lessey BA \& Giudice LC 2002 Global gene profiling in human endometrium during the window of implantation. Endocrinology 143 2119-2138.

Kitaya K, Nakayama T, Daikoku N, Fushiki S \& Honjo H 2004 Spatial and temporal expression of ligands for CXCR3 and CXCR4 in human endometrium. Fournal of Clinical Endocrinology and Metabolism 89 2470-2476.

Lessey BA 2002 Adhesion molecules and implantation molecules. Journal of Reproductive Immunology 55 101-112.

Liang P \& Pardee AB 1992 Differential display of eukaryotic messenger RNA by means of the polymerase chain reaction. Science 257 967-971.

Lindsay AJ, Hendrick AG, Cantalupo G, Senic-Matuglia F, Goud B, Bucci C \& McCaffrey MW 2002 Rab coupling protein (RCP), a novel Rab4 and Rab11 effector protein. Fournal of Biological Chemistry 277 12190-12199.

Prekeris R, Davies JM \& Scheller RH 2001 Identification of a novel Rab11/2 binding domain present in Eferin and Rip proteins. Fournal of Biological Chemistry 276 38966-38970.

Rosario G, Sachdeva G, Okulicz, WC, Ace CI, Katkam RR \& Puri CP 2003 Role of progesterone in structural and biochemical remodeling of endometrium. Frontiers in Biosciences 8 S924-S935.

Sachdeva G, Shah CA, Kholkute SD \& Puri CP 2000 Detection of progesterone receptor transcript in human spermatozoa. Biology of Reproduction 62 1610-1614.

Sachdeva G, Patil V, Katkam RR, Manjramkar DD, Kholkute SD \& Puri CP 2001 Expression profiles of endometrial leukemia inhibitory factor, transforming growth factor $\beta 2$ and transforming growth factor $\beta 2$ receptor in infertile bonnet monkeys. Biology of Reproduction 65 1-8.

Semino G, Semino A, Pietra G, Mingari MC, Barocci S, Venturini PL, Ragni N \& Melioli G 1995 Role of major histocompatibility complex class I expression and natural killer-like T cells in the genetic control of endometriosis. Fertility and Sterility 64 909-916.

Spencer TE \& Brazer FW 2002 Biology of progesterone action during pregnancy recognition and maintenance of pregnancy. Frontiers in Biosciences 7 D1879-D1898.

Stenmark H, Patron RG, Steele-Mortimer O, Lutcke A, Gruenberg J \& Zerial M 1994 Inhibition of Rab5 GTPase activity stimulates membrane fusion in endocytosis. EMBO Fournal 15 1287-1296.

Ullrich O, Reinsch S, Urbé S, Zerial M \& Parton RG 1996 Rabl1 regulates recycling through the pericentriolar recycling endosome. fournal of Cell Biology 135 913-924.

Urbe S, Huber LA, Zerial M, Tooze SA \& Parton RG 1993 Rab11, a small GTPase associated with both constitutive and regulated secretory pathways in PC12 cells. FEBS Letters 334 175-182.

Van der Sluijs P, Hull M, Webster P, MBle P, Goud B \& Mellman I 1992 The small GTP-binding protein Rab 4 controls an early sorting event on the endocytic pathway. Cell 70: 729-740.

Wallace PK, Yeaman GR, Johnson K, Collisons JE, Guyre PM \& Wira CR 2001 MHC class II expression and antigen presentation by human endometrial cells. Fournal of Steroid Biochemistry and Molecular Biology 76(1-5) 203-211.

Wang HQ, Takebayashi K, Tshchida K, Nishimura M \& Noda Y 2003 Follistatin regulated gene (FLRG) expression in human endometrium: sex steroid hormones regulate the expression of FLRG in cultured endometrial stromal cells. Fournal of Clinical Endocrinology and Metabolism 88 4432-4439.

Wilcke M, Johannes L, Galli T, Mavau V, Goud B \& Salamero J 2000 Rabl1 regulates the compartmentalization of early endosomes required for efficient transport from early endosomes to the trans-Golgi network. Fournal of Cell Biology 151 1207-1220.

Received 17 May 2005

Accepted 29 June 2005

Made available online as an Accepted Preprint 29 July 2005 